\title{
Empirical and Computational Issues of Microclimate Simulation
}

\author{
Aida Maleki, Kristina Kiesel, Milena Vuckovic, and Ardeshir Mahdavi \\ Department of Building Physics and Building Ecology, \\ Vienna University of Technology, Vienna, Austria \\ \{aida.gavgani, kristina.kiesel, milena.vuckovic, bpi\} @tuwien.ac.at
}

\begin{abstract}
The dynamic variability of weather conditions and complex geometry and semantics of urban domain impose significant constraints on the empirical study of urban microclimate. Thus, numerical modeling is being increasingly deployed to capture the very dynamics of urban microclimate. In this context, the present paper illustrates the basic processes of calibrating and preparing a numerical model for the simulation of the urban microclimate.
\end{abstract}

Keywords: Urban climate, Modeling, Evaluation, CFD.

\section{Introduction}

Urban microclimate displays a considerable variance due to the differences in morphology and density of urban spaces and the thermal and radiative properties of surfaces $[1,2]$. Microclimate conditions are affected by two main parameters: the local weather conditions and the urban fabric at the very location [3,4]. Random weather patterns and the wide variances of the urban geometry impose significant limitations regarding purely empirical microclimatic studies such as simple on-site collection of weather data [5]. Hence, detailed numerical models are being increasingly deployed as they can provide additional information toward urban microclimate analyses. The numerical simulation thoroughly deals with the complexities and nonlinearities of the urban climate systems $[2,6]$.

In this context, the present study addresses the use of numerical tools for the simulation of urban microclimates. As such, an increasing number of differing tools are becoming available for microclimatic modeling of urban areas [7]. Some tools are rather limited in terms of the range of pertinent variables they can consider. Other, more detailed tools display limitations in terms of domain size and resolution. Nonetheless, numerical models still present a valuable resource for the assessment of complex thermal processes in the urban field. For the purposes of the present contribution, we focus on a state of art CFD-based numeric simulation environment (ENVI-met [8]). We describe the general structure of ENVI-met, its features and limitations, and the model calibration process (including the application of sensitivity analysis). 


\section{Methodology}

\subsection{Overview of the Deployed Modeling Tool}

The tool ENVI-met was selected as it has the capability to simulate the urban microclimate while considering a relatively comprehensive range of factors (complex building shapes, vegetation and different types of pavements, etc.). The high-resolution output generated by this tool includes air, soil and surface temperature, air and soil humidity, wind speed and direction, short wave and long wave radiation fluxes, gas particles and many other important metrological factors.

ENVI-met 3.1 was deployed at the early stage of our inquiry. Additional simulations were run in version 4.0 and the results were compared.

General Structure. ENVI-met is a 3-dimensional non-hydrostatic model fit for the simulation of surface-plant-air interactions within urban environments. It is a microscale model with a time step between 1 to 10 seconds and resolution that ranges from 0.5 to $10 \mathrm{~m}$, for the grid length $(\mathrm{x})$ and the width $(\mathrm{y})$. Height of the grids $(\mathrm{z})$ can be more than $10 \mathrm{~m}$. ENVI-met calculates the dynamics of microclimate during a diurnal cycle (24 to 48 hours) using the fundamental laws of fluid dynamics and thermodynamics [9]. An overview of the data flow within the ENVI-met is given in Figure 1.

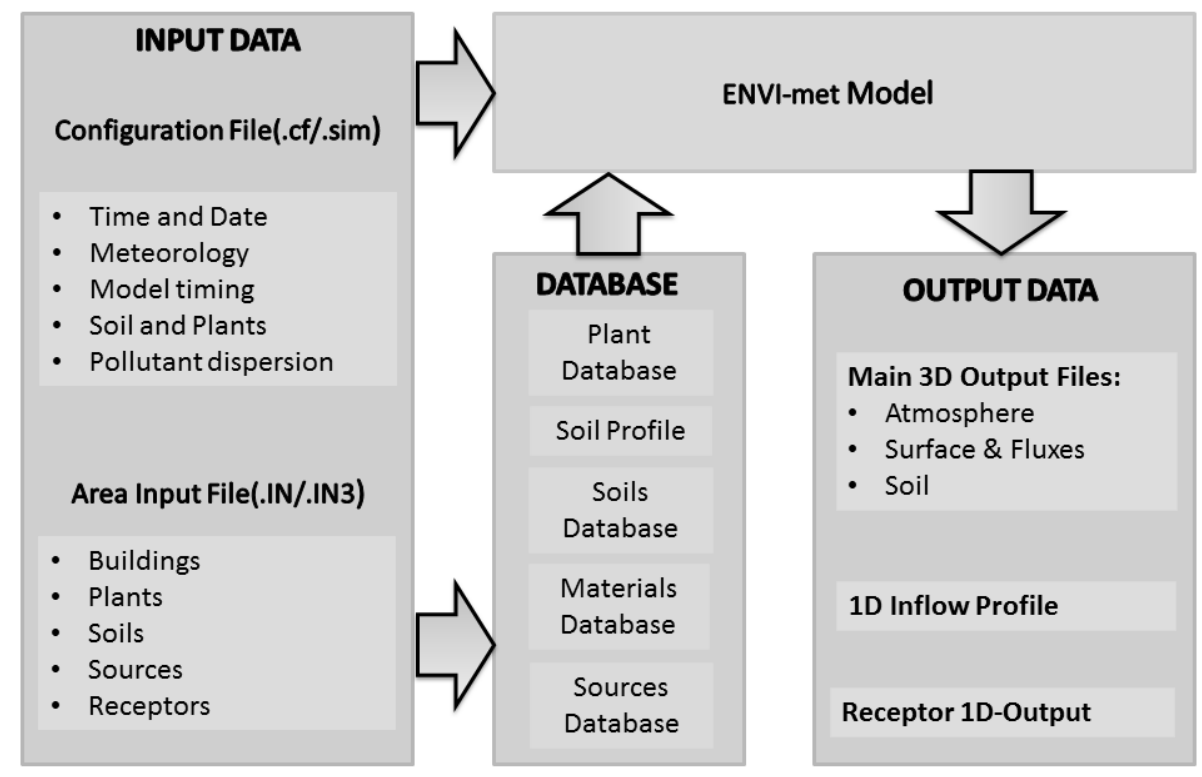

Fig. 1. The overview over the data flow within the ENVI-met

Model Layout. The ENVI-met model consists of three main components: 1D boundary model, 3D atmospheric model, and 1D soil model. The one dimensional boundary model expands from ground level to the height of $2500 \mathrm{~m}$ and defines the values 
of the model boundary. The Three-Dimensional atmospheric model incorporates rectangular grids with the dimension of $\mathrm{x}, \mathrm{y}$, and $\mathrm{z} . \Delta \mathrm{x}$ and $\Delta \mathrm{y}$ are constant throughout the model, although $\Delta \mathrm{z}$ can be set to increase with the height of model. Every grid can be completely filled by a building volume or just by the air. The grid size of the one dimensional boundary model is the same as of the 3D model, but in the case of the 1D soil model, the vertical size of the grid is defined by the model. The 1D soil model consists of 19 grid units and is extended down $4.5 \mathrm{~m}$ below the ground surface. A schematic overview of the model layout is shown in Figure 2.

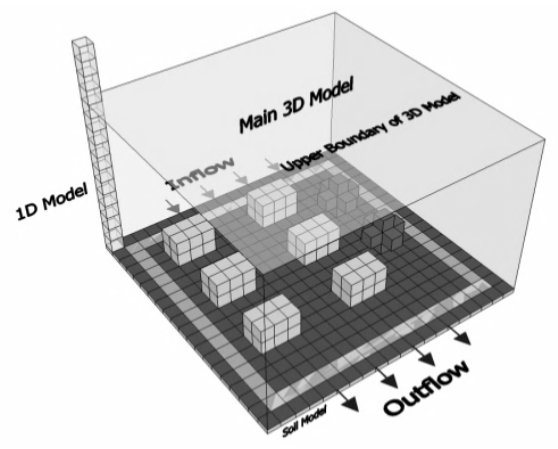

Fig. 2. The schematic overview of the model layout

\subsection{Calibration of the Model}

The accuracy of the microclimate simulation results is strongly dependent on the quality of the input data, and the initial/boundary conditions. Therefore, appropriate input data should be prepared for the simulation. Ideally, an optimization-supported approach can be used toward an automated model calibration process [10]. However, such an approach faces major computational challenges if applied in the urban simulation domain: Complexity of the climatic simulation models and the highly timeintensive simulation runs make comprehensive optimization-based calibration rather infeasible. Thus, in the present case, calibration relied on a heuristically guided trial and error process based on a small control area (as shown in Figure 3, area bound by the dashed rectangle) in the city of Vienna, Austria.

Two stationary weather stations (BPI and $\mathrm{C}^{*}$ ) are located in the selected area, monitoring the conditions constantly. The BPI weather station is located at the highest point of the Vienna University of Technology, above the urban canopy, without any obstacles blocking the sky - Sky View Factor $(\mathrm{SVF})=1$. Therefore, it represents a good model receptor location to evaluate the ability of the software to predict the solar radiation. The second stationary weather station $\mathrm{C}^{*}$ is located inside the urban canopy, at the height of $7 \mathrm{~m}$, and records the weather condition continuously. The data obtained from this station was used to evaluate the accuracy of the simulation outputs for the urban canopy.

As it is shown in Figure 3, the input data of the simulation model is composed of two types of data, the weather data and geometry/materials of the area. Since the geometry of the area is not subjected to calibration, the geometrical model was 


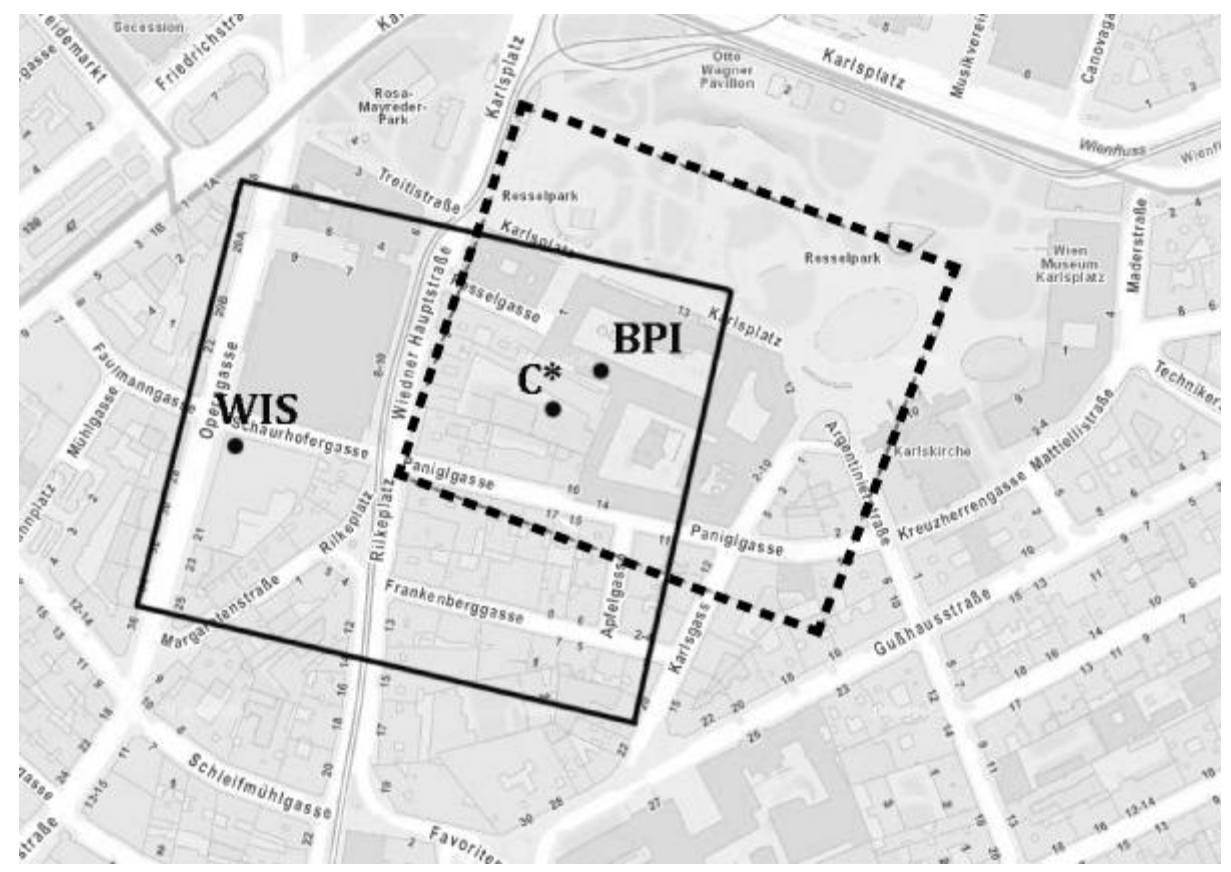

Fig. 3. The plan of the selected areas for model calibration and application

generated with relatively low resolution (the grid size equal to $5 \times 5 \times 2$ ) to accelerate the calibration process.

In order to determine the optimal settings for the initial/boundary conditions, a number of trial runs were conducted. Several combinations of input variable options were probed until an acceptable convergence of the simulated and measured results was achieved.

To evaluate the offset between the modelling results and the values obtained through measurements, three different indicators were defined. First indicator was the index of agreement (d) suggested by (Willmott 1982). Index of agreement is a descriptive measure and can be applied to make Cross-Comparison between models as a relative and bounded measure. Index of agreement (d) is calculated as follows:

$$
d=1-\frac{\sum_{i}^{n}\left(s_{i}-m_{i}\right)^{2}}{\sum_{i}^{n}\left(\left|s_{i}^{\prime}\right|-\left|m_{i}^{\prime}\right|\right)^{2}} \quad 0 \leq d \leq 1
$$

where $s_{i}^{\prime}=s_{i}-\bar{m}$ and $m_{i}^{\prime}=m_{i}-\bar{m}, \bar{m}$ is the mean value of measured variables, $\mathrm{m}_{\mathrm{i}}$ is the measured variable, and $s_{i}$ the simulated one.

The second used indicator was the Root Mean Square Deviation (RMSD) or RootMean Square Error (RMSE), a measure of the differences between outcomes of a model and the associated observed values. RMSE is a good measure to show the accuracy by comparing different prediction errors within a dataset, lower values indicate less error in prediction. It is calculated using the following formula: 


$$
R M S E=\sqrt{\frac{\sum_{i=1}^{n}\left(m_{i}-s_{i}\right)^{2}}{n}}
$$

And the third indicator was the Coefficient of Variation of the Root Mean Square Deviation CV (RMSE), and is calculated by:

$$
\mathrm{CV}(\mathrm{RMSE})=\left(\frac{R M S E}{\bar{m}}\right) \times 100
$$

These indicators were used in each of the modelled scenarios to obtain the offset between the measured values and the simulation results concerning air temperature and solar radiation for both, aforementioned receptors.

Table 1. Simulation input data for various model calibration stages (simulations conducted for

\begin{tabular}{|c|c|c|c|c|c|c|}
\hline \multirow{6}{*}{$\begin{array}{l}\text { Basic } \\
\text { data }\end{array}$} & Scenarios & $\mathbf{0}$ & Ia & Ib & II & III \\
\hline & ENVI-met Version & 3.1 & 3.1 & 4 & 4 & 4 \\
\hline & $\mathrm{W}$ Wind Speed $\left[\mathrm{m} \cdot \mathrm{s}^{-1}\right]$ & 0.2 & 2 & 2 & 2 & 2 \\
\hline & $\begin{array}{ll}\text { Initial } & \text { Temperature } \\
{[\mathrm{K}]} & \\
\end{array}$ & 301 & 303 & 303 & 303 & 303 \\
\hline & Solar Adjustment & 1 & 0.82 & 0.82 & 0.82 & 0.82 \\
\hline & $\begin{array}{ll}\text { Specific } & \text { Humidity } \\
{\left[\mathrm{g} / \mathrm{kg} \mathrm{air}^{-1}\right]} & \\
\end{array}$ & 7 & 8 & 8 & 8 & 8 \\
\hline \multirow{2}{*}{ Buildings } & Albedo Walls & 0.2 & 0.4 & 0.4 & 0.4 & 0.4 \\
\hline & Albedo Roofs & 0.2 & 0.4 & 0.4 & 0.4 & 0.4 \\
\hline \multirow{9}{*}{$\begin{array}{l}\text { Simple Forc- } \\
\text { ing }\end{array}$} & Max temperature $[\mathrm{K}]$ & --- & --- & --- & 306.85 & 306.85 \\
\hline & $\begin{array}{l}\text { Time of Max temper- } \\
\text { ature }\end{array}$ & $\begin{array}{ll}-- \\
-\cdots\end{array}$ & --- & $-\cdots$ & $16: 00$ & $16: 00$ \\
\hline & Min temperature [K] & --- & --- & --- & 295.15 & 295.15 \\
\hline & $\begin{array}{l}\text { Time of Min tem- } \\
\text { perature }\end{array}$ & --- & --- & --- & 04:00 & 04:00 \\
\hline & $\begin{array}{l}\text { Max relative humidi- } \\
\text { ty }[\mathrm{K}]\end{array}$ & $-\cdots$ & --- & -- & 76 & 76 \\
\hline & $\begin{array}{l}\text { Time of Max relative } \\
\text { humidity }\end{array}$ & $--\cdot$ & --- & --- & 04:00 & 04:00 \\
\hline & $\begin{array}{l}\text { Min relative humidity } \\
{[\%]}\end{array}$ & --- & --- & --- & 39 & 39 \\
\hline & $\begin{array}{l}\text { Time of Min relative } \\
\text { humidity }\end{array}$ & -- & --- & --- & $17: 00$ & $17: 00$ \\
\hline & Forcing & --- & --- & --- & hourly & $\begin{array}{l}\text { Min / } \\
\operatorname{Max}\end{array}$ \\
\hline
\end{tabular}
a location in Vienna, $22^{\text {nd }}$ of July 2010, wind direction $=163^{\circ}$, relative humidity $=57 \%$ ) 
The calibration process proceeded as follows. Slight modifications to the starting model input assumptions for trial runs (Scenario 0 in Table 1) using ENVI-met 3.1 ("none-forcing" mode) resulted in the input data set of Scenario Ia and a better predictive performance. Subsequently, the use of the same input information (Scenario Ib) with the updated ENVI-met 4.0 further improved the results, albeit slightly. Since ENVI-met 4.0 introduced the possibility of user defined diurnal variations of atmospheric boundary conditions (forcing), allowing the creation of user specific weather scenarios, this new feature was tested within the Scenario II (hourly forcing). Again, an improvement was achieved. However, the forcing option with minimum and maximum air temperature values (Scenario III) did not result in improvements.

The respective statistics pertaining to the comparison of modelled and measured results are given in tables 2 to 4 .

Table 2. d, RMSE, and CV (RMSE) for comparison of simulated temperatures with weather station measurements (BPI)

\begin{tabular}{cccccc}
\hline Scenarios & 0 & Ia & Ib & II & III \\
\hline $\mathrm{d}$ & 0.50 & 0.88 & 0.92 & 0.95 & 0.92 \\
\hline $\mathrm{CV}(\mathrm{RMSE})[\%]$ & 11.04 & 7.84 & 6.32 & 4.51 & 11.04 \\
\hline RMSE $[\mathrm{K}]$ & 3.15 & 2.24 & 1.80 & 1.29 & 3.15 \\
\hline
\end{tabular}

Table 3. d, RMSE and CV (RMSE) for comparison of simulated global solar irradiance values with measurements (BPI)

\begin{tabular}{ccccc}
\hline Scenarios & $\mathbf{0}$ & Ia & Ib & II - III \\
\hline $\mathrm{d}$ & 0.98 & 1.00 & 0.99 & 1.00 \\
\hline CV(RMSE) [\%] & 13.82 & 5.05 & 10.44 & 6.45 \\
\hline RMSE [W.m $\left.{ }^{-2}\right]$ & 73.81 & 27.00 & 55.79 & 34.45 \\
\hline
\end{tabular}

Table 4. d, RMSE, and CV (RMSE) for comparison of simulated temperatures with measurements $\left(\mathrm{C}^{*}\right)$

\begin{tabular}{cccccc}
\hline Scenarios & 0 & Ia & Ib & II & III \\
\hline $\mathrm{d}$ & 0.67 & 0.91 & 0.94 & 0.97 & 0.95 \\
\hline $\mathrm{CV}$ (RMSE) $[\%]$ & 9.25 & 6.89 & 5.30 & 3.36 & 10.04 \\
\hline RMSE $[\mathrm{K}]$ & 2.64 & 1.97 & 1.51 & 0.96 & 2.87 \\
\hline
\end{tabular}

Given these results, the input value set of scenario II was selected as the most appropriate one for the intended simulation studies.

\subsection{Illustrative Use of the Calibrated Simulation Model}

The Model. To illustrate the application of the calibrated model, a slightly larger urban domain was selected (see Figure 3, rectangle with continuous boundary). 
The size of the modelled area was 296 by $296 \mathrm{~m}$, which allowed for the complex building structure to be modelled in higher detail. Two stationary weather stations are located within the boundaries of the study area. First one is BPI and the second one WIS ("Wien, Innere Stadt"), operated by the Central institute for meteorology and geodynamic (ZAMG).

Sensitivity Analysis of the Grid Size. In order to examine the sensitivity of the simulation results with respect to the grid size, three identical models with different grid sizes $(3 \times 3 \times 2),(4 \times 4 \times 2)$, and $(5 \times 5 \times 2)$, were generated. The weather data collected by WIS was used for forcing the diurnal variations of atmospheric boundary conditions. The $3 \times 3 \times 2$ model produced erroneous results, thus it was ignored. The models with 4 $\mathrm{m}$ and $5 \mathrm{~m}$ grid sizes, named $4 \mathrm{~m}-\mathrm{w}$ and $5 \mathrm{~m}-\mathrm{w}$ respectively, were used for further analysis. These models were used to compute temperatures for a day in summer 2011 at two locations corresponding to BPI and WIS weather station locations. Table 5 shows the summary of the statistics pertaining to the comparison of the simulation results with the corresponding measurement results. The difference between the two is not significant, but due to a higher resolution and potential of having more detailed outputs, model with $4 \mathrm{~m}$ grid size was selected as the most appropriate for subsequent inquiries.

Table 5. Predictive performance of the calibrated urban microclimate model

\begin{tabular}{llllcccccc}
\hline \multirow{2}{*}{ Model } & $\begin{array}{l}\text { grid } \\
\text { size }\end{array}$ & $\begin{array}{l}\text { Forced } \\
\text { by }\end{array}$ & & \multicolumn{3}{c}{ at BPI } & \multicolumn{3}{c}{ at WIS } \\
\cline { 4 - 9 } & RMSE & CV & d & RMSE & CV & d \\
\hline $4 \mathrm{~m}-\mathrm{w}$ & $4 \mathrm{~m}$ & WIS-data & 1.54 & 5.54 & 0.95 & 0.88 & 3.10 & 0.99 \\
\hline $5 \mathrm{~m}-\mathrm{w}$ & $5 \mathrm{~m}$ & WIS-data & 1.59 & 5.74 & 0.95 & 0.78 & 2.75 & 0.99 \\
\hline
\end{tabular}

Future Applications. A process was demonstrated to calibrate a comprehensive urban microclimate simulation tool with the aid of limited measurement data. The calibrated tool displays improved predictive performance and can be used to evaluate the effect of different urban intervention scenarios (e.g. mitigation measures pertaining to the Urban Heat Island phenomena) on the respective temporal and spatial variance of urban microclimate. Such interventions imply certain changes to specific urban features such as areas of vegetation, bodies of water, surface properties of constituent materials in the urban canyon, etc. The outcome of such parametric simulation-based analyses of urban intervention scenarios can provide valuable feedback to the decision makers toward more sustainable urban environment design and maintenance practices. 


\section{References}

1. Oke, T.R.: The energetic basis of the urban heat island. Quarterly Journal of the Royal Meteorological Society 108(455), 1-24 (1982)

2. Arnfeld, A.J.: Two decades of urban climate research: a review of turbulence, exchanges of energy and water, and the urban heat island. International Journal of Climatology 23(1), 1-26 (2003)

3. Katzschner, L., Thorsson, S.: Microclimatic Investigations as Tool for Urban Design. In: 7th International Conference on Urban Climate, Yokohama, Japan, 29 June-3 July (2009)

4. Kurbjuhn, C., Goldberg, V., Westbeld, A., Bernhofer, C.: Impact of different urban structures on the microclimate in the city of Dresden, Germany, EGU General Assembly 2010, Vienna, Austria, May 2-7 (2010)

5. Bourikas, L., Shen, P., James, A.B., Chow, D.H.C., Jentsch, M.F., Darkwa, J., Bahaj, A.S.: Addressing the Challenge of Interpreting Microclimatic Weather Data Collected from Urban Sites. Journal of Power and Energy Engineering 1, 7-15 (2013)

6. Yao, R., Luo, Q., Gao, Y.: Simulation of urban microclimates. In: CIBSE ASHRAE Technical Symposium, Imperial College, London, UK, April 18-19 (2012)

7. Mirzaei, P.A., Haghighat, F.: Approaches to study Urban Heat Island - Abilities and limitations. Building and Environment 45, 2192-2201 (2010)

8. Huttner, S., Bruse, M.: Numerical modelling of the urban climate - A preview on ENVImet 4.0. In: 7th International Conference on Urban Climate ICUC-7, Yokohama, Japan, 29 June-3 July (2009)

9. Elnabawi, M.H., Hamza, N., Dudek, S.: Use and evaluation of the ENVI-met model for two different urban forms in Cairo, Egypt: measurements and model simulations. In: 13th Conference of International Building Performance Simulation Association, Chambéry, France, August 26-28 (2013)

10. Taheri, M., Tahmasebi, F., Mahdavi, A.: A case study of optimization-aided thermal building performance simulation calibration. In: 13th Conference of International Building Performance Simulation Association, Chambéry, France, August 26-28 (2013) 